To be published in Carvalho, Maria José; Sequeiros, Paula; Capinha, Graça (org.) - A Investigação e a Escrita: Publicar sem Perecer.

Coimbra: IUC, 2021

\title{
Palavras como flores, conceitos como cercas: literacia da informação, desigualdades sociais no ensino superior
}

\author{
Paula Sequeiros \\ Centro de Estudos Sociais, Universidade de Coimbra \\ paulasequeiros@ces.uc.pt
}

\section{Resumo}

Abordagem a alguns conceitos de literacia, enfocada na literacia informacional, questionando a sua operacionalidade em programas de formação no ensino superior dirigidos a esta literacia. A seleção de conceitos baseia-se no requisito de que os paradigmas que os conformam permitam atender às desigualdades sociais nos processos de aprendizagem. Apresentam-se os conceitos de Paul G. Zurkowski, Paulo Freire e Walter Mignolo, e comenta-se a sua pertinência face a esta problemática.

\section{Palavras-Chave}

programas de formação; alfabetização crítica; alfabetismo alfabético; literacia da informação; democracia; colonialismo

\section{Abstract}

Some concepts of literacy are presented and their operability in information literacy in higher education training programs is questioned. 
The selection of conceptual approaches is based on the requirement that their paradigmatic framing should allow social inequalities in learning processes to be addressed. The concepts developed by Paul G. Zurkowski, Paulo Freire and Walter Mignolo are presented, and their relevance to this problematics is commented.

\section{Keywords}

training programmes; critical literacy; alphabetic literacy; information literacy; democracy; colonialism 
Página em Branco 


\section{Abordagens concetuais às literacias, operacionalidade face às desigualdades no ensino superior}

Detenho-me numa escrita em ensaio, esperando que seja encontro e partilha, visando propostas a concretizar. O ensejo deste trabalho decorre das ações extra-curriculares de literacia da informação promovidas pela Biblioteca Norte/Sul e em que participaram formandas e formandos com composição internacional e multilingue, maioritariamente em estudo pós-graduado no CES, U.C. (Carvalho, Veríssimo, Solovova \& Duxbury, 2018). Os debates entre formadoras e formadores dos ciclos Publicar sem perecer, sobreviver ao turbilhão, e as inconformações, críticas e regozijos das e dos aprendentes alimentaram esta reflexão.

Um percurso seletivo por diferentes conceitos de literacia, articuláveis com o da literacia da informação para o ensino superior, é o que proponho neste texto. Iniciado o percurso, pretendo ir questionando a operacionalidade dessas abordagens concetuais no que toca às desigualdades sociais em processos de aprendizagem no ensino superior, e por extensão em programas formativos, desigualdades construídas a partir de classes, sexos/géneros, raças/etnias, línguas, deficiências. Buscando a compaginação da injustiça social e da injustiça epistémica nessas abordagens, foram-se revelando áreas de cruzamento disciplinar a considerar.

Na procura de uma articulação possível entre literacia e educação superior, enfoco o texto em três autores como pontos de partida, sem dispensar outros no percurso. Um é Paulo Freire, por entender a alfabetização como requisito democrático, imbuindo os processos de 
ensino/aprendizagem de possibilidades emancipatórias, por conceber projetos coletivos de ler a palavra e ler o mundo, com aplicabilidade a outros níveis de ensino. Outro autor é Paul G. Zurkowski, introdutor do conceito de literacia da informação, permanecente nas aprendizagens e nas práticas do trabalho documental, configurado a partir de um modelo tecnocrático que carece de debate crítico atualizado. Walter Mignolo é o autor convocado por destacar a literacia alfabética como recurso na produção imperial do conhecimento em territórios do Novo Mundo, por relevar a destruição do conhecimento das margens como constitutiva da dominação colonial, tomando a letra e o livro como dispositivos centrais.

Refiro preliminarmente o livro de Andrew Whitworth como oportunidade e desafio crítico pela abordagem extensiva ao tema da literacia da informação (2015). Li os recentes contributos reunidos em «Celebrando Paulo Freire» (2019) e em «Reinventando Freire» (Carnoy \& Gadotti, 2018) com entusiasmo. Boaventura de Sousa, com "O fim do império cognitivo", fornece um manancial de inspiração, (Santos, 2018) gotejado na presente etapa do trabalho.

\section{Literacia tecno-informacional - Zurkowski}

Se o termo literacia da informação é familiar a muitas das e dos profissionais BAD (Bibliotecas, Arquivos e Documentação), a história da sua produção e autoria permanecem pouco conhecidas. Poderá surpreender a antecedência em décadas no uso de termos e ideias agora percebidos como familiares senão mesmo como dominantes. Convido de seguida a uma reflexão sobre aspetos marcantes na construção do conceito. 


\section{Transição para a economia da informação}

A explosão informativa, a incapacidade da pessoa comum para lidar com a superabundância documental, a nova economia da informação e a exigência de eficácia no trabalho do conhecimento, o desemparelhamento entre uma expansão necessária dos serviços de informação e um mercado da informação que carece de estímulo para crescer na medida do investimento das corporações, a adoção das novidades tecnológicas pelo mercado e a incipiente apetência dos consumidores, são questões que se cruzam e originam disfunções na nova economia. A solução é a compatibilização entre a oferta e o uso efetivo de informação no setor dos serviços de publicação de informação, onde as bibliotecas estão incluídas. Para tanto, o estado, em nome da liberdade de informação, deve assegurar que as corporações não se confrontem com a concorrência desleal de serviços públicos, dados à inércia por estarem fora da competição do mercado, nem com a expectativa de gratuitidade por parte dos consumidores. Os serviços de informação de ponta, já existentes no mercado, devem ser adquiridos pelas instituições de uso público, podendo ser pagos ou pelo usuário final ou pelas próprias instituições, quando financiadas pelo estado.

É desta forma que, em 1974, Paul G. Zurkowski, então presidente da Software and Information Industry Association, entende que o setor em expansão corre o risco de ser entravado, apesar de fundamental na transição para a nova economia, pelo que se posiciona no relatório que dirige à Comissão Nacional para as Bibliotecas e Ciência da Informação (1974). ${ }^{1}$ Aí argumenta que assegurar a provisão de

\footnotetext{
${ }^{1}$ National Commission on Libraries and Information Science, órgão consultivo da Presidência e do Congresso dos EUA, com competência para desenvolver estudos e programas nacionais sobre necessidades de informação, aconselhar entidades federais, estaduais e locais públicas e privadas, aprovar programas e financiamento.
} 
sistemas de informação e de publicação avançados e a formação no seu uso, permitirá fazer corresponder a quantidade e a variedade das fontes e dos produtos informativos, mal utilizados e mal conhecidos, às necessidades de informação dos indivíduos nos EUA. Porque a designada «atividade de informação e publicação» regista importância e evolução crescentes, Zurkowski antecipa que ela tem capacidade para gerar resultados muito avultados. ${ }^{2}$ Apela, por isso, a medidas governamentais prioritárias que facilitem a reorganização empresarial e a formação para a transição económica.

Em «Relações e prioridades do ambiente do serviço de informação», o documento propõe um «programa nacional para a

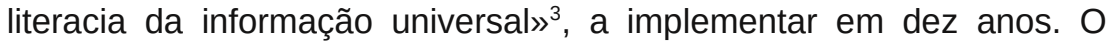
objetivo é expandir o uso dessa nova habilidade profissional, cívica, educacional e de consumo que sumariamente define como a capacidade humana de lidar eficientemente com a informação para a resolução de problemas na nova economia.

\section{Trabalho na economia do conhecimento}

Centrado na eficiência no trabalho, o relatório faz recomendações confinadas aos resultados produzidos pelos «trabalhadores do conhecimento». Este termo era então vulgarizado por Peter Drucker (1909-2005) e Zurkowski explicita a influência que dele recebeu. Por isso, e para enquadrar as linhas de força económicas e políticas que ligam o relatório à denominada escola da gestão moderna em que Drucker se destacava, relevo algumas das suas ideias centrais.

\footnotetext{
${ }^{2}$ Esta a traduções seguintes de elaboração da autora.

${ }^{3}$ para toda a nação; também designada como total.
} 
Viver na Era da descontinuidade (Drucker, 1967), com referência à economia do passado recente, é para Zurkowski motivo de entusiasmo já que o presente se lhe apresenta pleno de oportunidades de evolução. Drucker adiantará que o se que espera dos trabalhadores do conhecimento é, mais que eficiência, é eficácia (1967a). Um trabalhador deste tipo, diferentemente do industrial, é mais escolarizado, tem alguma autonomia e conexão com outros trabalhadores intelectuais, possuindo especialidades que tornam incompatível a supervisão costumeira. Numa pretendida rutura temporal, espera-se que ele aprenda o que importa para e dentro da empresa e que assegure que sejam feitas, não muitas, mas as coisas certas.

Se a eficácia não está garantida (Drucker, 1967a, p.3-4) e a supervisão direta é inviável, é o quadro ideológico desenhado na organização que incitará os trabalhadores. Crescendo da competição interindividual, o sucesso no trabalho é o fim último, a recompensa maior a excelência atingida, o prémio a ascensão na escala de poder. Ser executivo é um alvo laboral e social (Drucker, 1967; 1967a), ser eficaz, um imperativo tanto económico como moral. O melhoramento social deve ser assegurado pela concorrência entre indivíduos, já que quem sobrevive é o mais habilitado.

Brevemente entendo questionar essa visão gestionarista. Em primeira instâmcia, por ofuscar a relação económica e as tensões constituintes do trabalho. Floreada como requisito para a recompensa individual, justifica a competição entre quem trabalha, omite o regime de propriedade da empresa e do trabalho e silencia a origem e o destino da riqueza produzida.

\section{A eficiência na economia da informação}


O modelo tecno-informacional que Zurkowski apresenta como inovador dá forma e confere sentido à sua concetualização de atividades e usos do serviço de «publicação de informação». ${ }^{4} \mathrm{Em}$ apoio à sua argumentação, compara-o com o modelo tradicional, em declínio.

Partindo da narrativa textual e imagética e da argumentação contida no relatório, detenho-me na análise de como esta comparação revela questões basilares sobre o que move Zurkowski. Faço-o por que este tipo de projeto continua a ser concretizado em várias geografias nos dias de hoje, e também porque, paradoxalmente, apesar da influência permanecente do enquadramento político implícito, o seu relatório é mal conhecido. Avanço assim uma análise crítica de texto em contexto.

Usando uma forma de expressão que the era familiar, a fluxogramação, o relator desenha uma comparação entre os setores inovador e o tradicional.

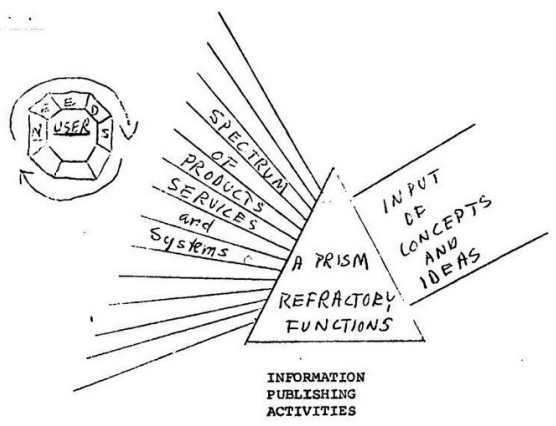

[ativ public informacao.jpg]

Figurativamente é feita uma analogia entre as atividades de publicação de informação e um prisma ótico. Nele se refratam os inputs, um feixe de ideias e conceitos, em outputs, um espetro de produtos, serviços e sistemas que vão irradiar um usuário-tipo

${ }^{4}$ tradução literal; atividades que correspondem parcialmente à designação portuguesa da Classificação das Atividades Económicas, CAE revisão 3, Actividades de Informação e de Comunicação. 
polifacetado, dinâmico. O texto descreve as atividades do setor, onde inclui, entre outras, as de bancos de dados, de serviços e agências noticiosas governamentais ou privados, de serviços de marketing, de edição de publicações, de ensino e ainda de produção de equipamentos e programas informáticos.

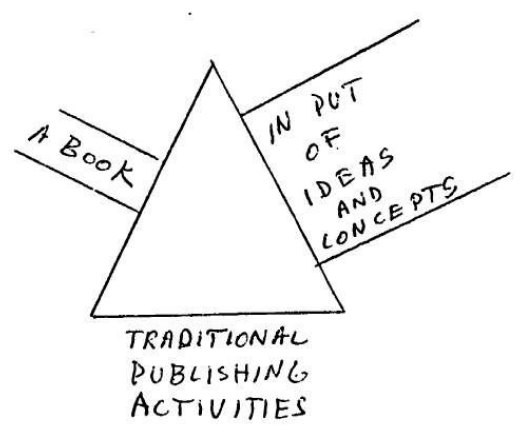

[ativ tradicionais.jpg]

As atividades de publicação tradicionais são figuradas numa analogia simplista: um feixe de inputs e um único output, o livro. A relação entre entradas e saídas é linear, mediada por uma forma plana, triangular. Aqui, livro é sinédoque de material impresso dado a atividade económica, alegadamente, permanecer centrada nele. Esvaziar o livro de significados históricos e sociais, desligando-o dos outros meios efetivamente abundantes senão predominantes -, resulta em representar a atividade editorial tradicional como sendo imóvel, uniforme, unidirecional, sem irradiação. $\mathrm{O}$ «tradicional» é figurado por retroprojeção: o antes na sequência do depois, como na publicidade depreciativa.

Zurkowski define como letrados em informação os consumidores capazes de «filtrar» fontes primárias e ferramentas e de as moldar às suas necessidades no trabalho. Estima que este grupo atinja «talvez um sexto» do total. Os demais, sabendo ler e escrever, por não saberem moldar a informação às suas necessidades, por carecerem de «uma medida para o valor da informação», são classificados como iletrados informacionais (1974, p.6-7). 
Em nenhuma das figurações estão a pessoa ou os grupos de leitores representados, o que reforça a ideia textualmente veiculada de que, como consumidores, se espera que comprem, não que intervenham.

Visando a transição para um paradigma de economia da informação, o relatório enumera atividades profissionais e elenca empresas habilitadas para tanto. Considerando a informação para o ensino superior, aqui em apreço, da enumeração retenho as empresas de produção de sumários científicos e noticiosos, de reprodução de artigos, de índices de citações, de publicação dos relatórios e contas, das perspetivas para os setores industriais e das decisões do Congresso. O setor informacional que arrancara no pós-guerra, emergia então nas participações financeiras das corporações. Zurkowski lista marcas e grandes grupos internacionais a operar em múltiplos subsetores, e recentemente também na informação, tais como Lockheed, McGraw-Hill, Dunn \& Bradstreet, Standard \& Poors, The New York Times. Assegurar ligações proveitosas entre as bibliotecas e esta economia da informação com fins lucrativos, seria o motivo maior para o desenvolvimento do campo da informação.

Sem história, nem sociedade, nem profundidade, relevo a articulação das ilustrações com a linguagem dos primórdios do capitalismo digital. Nessa linguagem, inovação tecnológica, privatização, desregulamentação para os setores mais lucrativos da economia - em contraste com intervenção requerida ao estado para garantir o mercado livre -, competição intensa no trabalho, são notas do leitmotiv neoliberal sobre as pautas dos «flagelos seculares do sistema de mercado: desigualdade e dominação» (Schiller, 1999, p.209). 


\section{As bibliotecas no sistema tecno-informacional}

Assumindo o copyright como um limiar na relação entre as bibliotecas e a indústria da informação, o relator considera longamente os prejuízos gerados pelas bibliotecas com a gratuitidade da cópia de informação e da prestação de serviços. O que entende ser concorrência desleal à economia da informação, já que as instituições e as empresas orientadas para o lucro visam o mesmo grupo de usuários. A informação ao leitorado deve ser paga. A fotocópia e a microfilmagem - eventualmente mais republicação do que cópia -, e mesmo as trocas interbibliotecárias, devem ser restringidas. $\mathrm{Na}$ mesma linha privatista, defende que o desenvolvimento de sistemas informáticos para bibliotecas seja externalizado.

Segue ainda Drucker (1967), e afirma que a impulsão para o agente económico não provém do gosto. O consumidor, enquanto tal, não é movido por sentimentos. O progresso informacional requer, sim, que aceite que «a informação tem valor na direta proporção do controle dado sobre o que é e o que pode tornar-se». Contudo, «muitos que estão conscientes da necessidade da informação sentem ainda que a informação, como o ar, é uma mercadoria grátis.» (Zurkowski, 1974, p.6). Introduzir o pagamento dos serviços nas bibliotecas, justifica, propicia a aceitação de que lhe seja posto um preço.

Que papel reserva às bibliotecas nesse modelo de transição para economia da informação? No caso dos EUA, as bibliotecas eram entidades de propriedade público-privada ou não pública. Completando o cenário, Zurkowski propõe que se convertam em «pontos de retalho» no circuito de distribuição da economia da informação. Não sendo explícito o tipo de bibliotecas que visa, assumo que sejam sobretudo as académicas e científicas, as grandes fontes de rendimento para os serviços informacionais sofisticados que 
Zurkowski representa. Contudo, ocasionalmente, refere as bibliotecas públicas, sendo de realçar a frequência intensa que registavam naquele momento nos EUA. E no caso específico das bibliotecas federais, contrariando a sua tese de desenvolvimento através da inovação TIC, opõe-se à tendência recente para se converterem em centros de informação, de novo argumentando que os serviços especializados devem ser externalizados. Já a formação em literacia da informação à comunidade deve ser responsabilidade atribuída às bibliotecas por se enquadrar na sua atividade tradicional.

A argumentação política centra-se na necessidade de regular o ambiente de produção e as relações entre agentes. O receio expresso por Zurkowski é o da perda de independência: se mantido fora da economia que modeliza, o setor da publicação de informação precisa de apoio do estado e fica em perigo a liberdade de informação. Esta garante-se com uma pluralidade de canais e fontes e com um mercado livre, portanto sem subsídios ao serviço público.

\section{Notas de comentário}

O relatório apresenta incongruências e vazios, para além da ausência de nexo histórico. O futurismo de que se reveste não diferencia, antes encerra, o presente realmente existente num tempo aditivado, mas não mudado. Demonstra superficialidade na análise das relações entre subsetores, falta de finura ao desconsiderar os modos diferentes e cumulativos nos usos de recursos de informação e no acesso a canais informativos.

A categorização de todas as atividades de documentação e informação num só setor de publicação informação é confusa, a inclusão aí do ensino em totalidade é, no mínimo, excessiva. A omissão da leitura por prazer, o enfoque exclusivo nas atividades 
lucrativas da publicação de informação, a intenção expressa de colocar cercas de privatização em torno de serviços tradicionalmente públicos, relegam ao olvido muito do que em palavras, atraentes como flores, é nomeado: a informação para a cidadania e a democracia, para as dimensões da vida coletiva ou individual e fora dos limites do trabalho produtor de lucro.

Emerge assim uma narrativa em que o sujeito, mais que o relator individual, é um setor económico inebriado pela liderança globalizante. Para a narrativa, a economia liberalizada enaltece os valores da competição entre trabalhadores de novo tipo e converte em mercadoria realizações e relações, o marketing encena a persona do consumidor, para celebrar a economia da informação. Nesse cenário o conhecimento expulsa a ignorância engendrada pela inadaptação, em que não se revê nem social nem ideologicamente. A narrativa entusiasma-se em tecnocracia e teleologia - o desenvolvimento oligopolista é imparável -, apresenta-se redutora - não contém diversidade social - , sustenta-se numa irrealidade que suprime a pluralidade e a riqueza de formas e de finalidades nos usos da informação.

\section{Literacia para a práxis democrática - Paulo Freire}

Alfabetizar criticamente é um imperativo de justiça social e uma componente da práxis democrática de que Paulo Freire não prescindiu. A visão que vai construindo sobre a entrada no mundo da leitura e da escrita assinala a condescendência no ensino e, em simultâneo, apela repetidamente à exigência no processo educativo. Antes que tudo, Freire posiciona-se ao repensar a leitura: outro olhar, outro rumo, outra 
bagagem - nem ferramenta de levar para casa, nem capacidade de descodificação revelada, nem elevação da cultura, Como desenvolverei, a «leitura do mundo precede [...] a leitura da palavra» é frase-guia que estabelece um primado - cada aprendente carrega já consigo uma forma de ler - que propicia uma relação não hierarquizante na educação popular e que interliga o biográfico individual e social com a descoberta e que orienta para ação emancipatória.Proponho-me de seguida ir respondendo à pergunta: porque e como ligar projetos de alfabetização à literacia da informação? Sendo a alfabetização associada a um aprender iniciante, como pode a escola freireana beneficiar um debate sobre uma literacia avançada?

Uma forma divergente de pensar e praticar a literacia surge num momento histórico coincidente com o do relatório Zurkowski. Dos inícios da década de $1960^{5}$, durante a de 1970, a partir do Brasil e de outros países da América Latina, Paulo Freire age e escreve para a alfabetização. Se essa coincidência pode surpreender, compreender a impulsão emancipadora, alternativa, contracultural do movimento freireano, dissipa outras coincidências. Pelo contrário, ganha destaque o que Freire entende por novo, às necessidades de quem se dirige, os meios a que recorre, a imaginação e colaboração que promove (1989). A singeleza da linguagem e dos processos, só aparentemente simples, alimentam e sustentam programas de uma práxis pedagógica e social exigentes. Falam-se as dificuldades, pensam-se as flores, levantam-se as cercas.

A espaços, referirei aspetos contextuais relativos ao desenvolvimento do seu pensamento para cotejo com outros programas e autores.

\footnotetext{
${ }^{5}$ De 1963, em Angicos, Estado do Rio Grande do Norte, chega o registo da primeira ação de alfabetização de Freire.
} 


\section{Analfabetismo, estigma da globalização}

Pouca gente sabia ler e escrever no Brasil e noutros países, então designados atrasados, do terceiro mundo. Em comparações internacionais, a quantificação do analfabetismo, sem a crítica sobre os lugares económico-sociais e imperiais da sua produção, era usada para desresponsabilizar os poderes, julgar os oprimidos e ainda para relegar os saberes próprios, ancestrais e contemporâneos. Se o analfabetismo estava presente nos EUA mesmos, centro do primeiro mundo, um estigma de inapetência e de inaptidão era reconfigurado a partir de uma «inferioridade intrínseca de certas classes ou grupos sociais» (Freire, 1981, p.38). De colonizadas, a nova ordem política mundial reclassificava-as como analfabetas através de uma bitola funcional. Assim se ressignificavam pessoas no fundo das tabelas do subdesenvolvimento, as quais subnutridas, aguardavam pela ajuda externa para serem «alimentadas» com palavras. Preocupação que Freire manifesta, naqueles anos, contundentemente:

[Uma das características da visão ingénua é] o caráter mágico emprestado à palavra escrita, vista ou concebida quase como uma palavra salvadora [...]. O analfabeto, porque não a tem, é um «homem perdido», cego, quase fora da realidade. É preciso pois, salvá-lo, e sua salvação está em passivamente receber a palavra uma espécie de amuleto - que a «parte melhor» do mundo Ihe oferece benevolamente. Daí que o papel do analfabeto não seja o de sujeito de sua própria alfabetização, mas o de paciente que se submete docilmente a um processo em que não tem ingerência. (1989, p.18). 
Com uma visão de amplitude global e ciente das alterações vividas durante os anos 70, preocupado com o ensino e a informação a que tem acesso a maioria da população tanto nos EUA como no seu país, o analfabetismo é enfrentado como obstáculo à democracia.

Ao considerar as possibilidades emancipatórias da alfabetização crítica, tais como decidir autonomamente e votar, Freire confronta o modelo progressivamente dominante de ensino. A escola, assim modelada, é uma instituição que tanto reproduz as desigualdades como as legitima, como ainda silencia as condições da produção desigualitária. Se a aprendizagem é um problema intrinsecamente educacional, se não se liga às condições de dominação e exploração vividas pelos aprendentes nem às políticas educativas, se está centrada na resolução mecânica de operações - ler, escrever, contar -, a alfabetização é peça de uma máquina que ingerindo desigualdades, adornadas as expele.

\section{O propósito e o móbil da ação}

Freire e seus colaboradores observaram, conversaram, participaram em atividades, identificando assim hábitos, problemas, saberes daquela população. Foi esta fase prévia de trabalho de pesquisa de carácter antropológico que Ihes permitiu identificar "temas geradores" e "palavras geradoras" e, com eles, conceber materiais e metodologias adequadas e significativas para aqueles adultos que, deste modo, se alfabetizaram (e conscientizaram) em 40 horas. E, sublinhe-se, a experiência de Angicos aconteceu ainda em 1963. (Cortesão, 2018a, p.48).

Freire torna claro o que o move e onde pretende chegar. Sem bitola civilizacional e de mente aberta, dirige-se ao extenso afazer educativo. 
Na sua fala, as palavras têm situação e dimensão diversa: parte de outro globo, matéria de leitura e de significação da palavra escrita e dita, pluralidade de locais a transformar socialmente. Alfabetização é termo que precisa de extravasar um ensino «elementar», tecnicamente inculcado e absorvido, de se alargar à relação entre aprendentes e o seu território, mediada pela prática transformadora desenvolvida dentro das comunidades e com elas.

\section{Ler e escrever o mundo, alfabetizar para emancipar}

Paulo Freire e Donaldo P. Macedo coligem, e publicam em 1987 nos EUA e em 2011 no Brasil, as ideias freireanas expressas desde os anos 60, impregnadas agora das experiências de alfabetização em diversos projetos (2011, p.4):

A fim de superar, pelo menos parcialmente, essa «crise da democracia», deve-se instituir uma campanha de alfabetização crítica [...] que transcenda o atual debate a respeito da crise da alfabetização [...], ou seja, a ideia de que a alfabetização é simplesmente um processo mecânico que enfatiza excessivamente a aquisição técnica das habilidades de leitura e de escrita.

Iniciado no rio Grande do Norte, os projetos situaram-se em países como a Guiné-Bissau (Freire e Macedo 2011) e Moçambique, São Tomé e Príncipe (Freire, 1989) e no Portugal pós-revolucionário (Cortesão, 2018 p.9-10).

Lembrando que nos próprios EUA o analfabetismo, pelo menos o designado funcional, atingia vários milhões de pessoas, a coletânea Alfabetização: leitura do mundo, leitura da palavra, rejeita o tecnicismo da literacia e o estigma asociado. 
A alfabetização proposta estende-se a «uma forma de política cultural». Não fixada numa definição, nem limitada num conceito, é tratada como processo dinâmico, em devir, como recriação, em partilha e em situação. Enriquecida, vai sendo trabalhada de forma radical, orientada para o empoderamento dos e das aprendentes:

Ler a palavra e aprender como escrever a palavra, de modo que alguém possa lê-la depois, são precedidos do aprender como «escrever» o mundo, isto é, ter a experiência de mudar o mundo e de estar em contato com o mundo (Freire e Macedo 2011, p.7).

A literacia sustenta-se, em conformidade, no saber que quem aprende traz consigo, da cultura oral, da experiência do trabalho ou da vivência em comunidade.

Formar letrados não se centra em adquirir capacidades ou ferramentas. Uma aprendizagem ativa requer questionar e tomar a palavra, construir discurso e significação da palavra e, no processo, ordenar o pensamento:

A leitura do mundo precede mesmo a leitura da palavra. Os alfabetizandos precisam compreender o mundo, o que implica falar a respeito do mundo (Freire e Macedo 2011, capo 1 ).

Nem utilitarista nem positivista, a lectoescrita pode conectar indivíduos e grupos diversos, unidos pela relegação às margens e pela conscientização da justeza em superar as desigualdades, na linha da Pedagogia do oprimido (Freire, 2018). ${ }^{6}$ Dos princípios da educação popular se assume que «a leitura da palavra» e a «leitura do mundo», ligadas na consciência social, não se podem dissociar nos processos

${ }^{6}$ Original de 1968, publicado a seguir ao exílio no Chile em espanhol, inglês e português. 
da escrita de uma outra realidade social. Da aglutinação de ideias, aí a palavra espantosa: ler a palavra inteira e significativa, é ler a «palavramundo» (1989, p.11), proporcionando uma abrangência e fundamentação sócio-política da aprendizagem (Carnoy \& Gadotti, 2018).

Impregnado da mescla de «curiosidade-espanto», o processo de aprendizagem cria as possibilidades de desconstruir e problematizar uma realidade existente, negativa.

Mais do que a solução, no imediato, é a «pedagogia da pergunta» que importa e forma (Freire \& Faundez, 1985; Guilherme, 2018, p.95).

Em contracultura, a pessoa educadora centra-se na escuta, não na transferência bancária de saberes; na dialogicidade, comunicando e significando em intersubjetividade, sem reverência por instituição ou professor; no projeto, em co-laboração e em devir, sem pronto a consumir da autoridade cognitiva legitimada (Monteiro 2019); na descoberta e interpretação a partir de temáticas geradoras, sem ventroloquismo nem copiagem; na abertura para os possíveis no humano, recusando a clausura dentro do realmente existente.

\subsection{Notas de comentário}

A par e passo realcei traços da pedagogia/ação de Freire questionando a sua operacionalidade para a literacia da informação em contexto formativo superior. Neste ponto, realço as possibilidades abertas para estimular práticas de aprendizagem orientadas para a democracia, num sistema de ensino crescentemente disputado pelo neoliberalismo, cercado pela ideologia da eficiência, da competição e do elitismo (Carnoy \& Blanco, 2000). E ainda pela necessidade de integrar nessas práticas as experiências de resistência a opressões trazidas e desenvolvidas durante a vida discente. 


\section{Literacia alfabética e imperialidade do conhecimento - Walter Mignolo}

Há palavras, línguas, escritas que impõem silêncio. Há formas extrativistas de conhecimento que deixam galerias vazias, destroem saberes tornados subalternos, impõem um monocolorismo cultural a vivências, grupos e territórios.

A descolonização epistemológica, para Mignolo, requer um programa de «aprender a desaprender para reaprender e reconstruir» (2011, p.26). Para isso, outros lugares de enunciação, das margens do poder - mais lugares de subalternidade do que fora de limites - devem ser buscados e assinalados. «Em lugar de ver as sociedades marginais a partir da perspetiva dos centros académicos», uma outra filosofia «propõe ver os centros culturais e políticos a partir do pensamento nas e das margens» (Mignolo, 2016, p.374-5).

Como se relacionam a destruição de conhecimento das margens, a literacia alfabética e a permanência do letramento colonial em sistemas educativos?

\section{1 - a colonialidade do poder e as margens}

Walter Mignolo aponta para a "colonialidade do poder" exercido pelo império como sistema que organiza e difunde recursos para sustentar a sua reprodução. Do conhecimento, à moralidade e à estética, o império explorou recursos para a criação de uma ordem que, para além de uma eloquente supremacia económica, estabeleceu uma silente hegemonia sobre sistemas de conhecimento. Pouco compreendidas, as consequências epistémicas do colonialismo são contudo danosas e persistentes até ao tempo presente, nas margens e no centro mesmo do império. Uma consequência é a hierarquização 
imposta de conhecimentos e de culturas. Descolonizá-los requer "repensar e reconcetualizar as histórias que têm sido contadas e a concetualização posta em prática para dividir o mundo entre cristãos e pagãos, civilizados e bárbaros, modernos e pré-modernos, e as regiões e pessoas desenvolvidas e subdesenvolvidas" (citado em Alcoff, 2017, p.38). Outra consequência é a subalternização da oralidade, face à letra, ao alfabeto, quando a «oralidade é um equivalente do alfabetismo e não o seu precursor antiquado» (Mignolo, 2016, p.255-6).

A partir da modernidade, a Europa criou discursos e mitos que legaram tropeços na produção e leitura de discursos e representações descoloniais. Para os superar, é necessário entender como traços deste sistema de dominação persistem, tanto em territórios outrora colonizados como colonizadores, e como se converteram em traços da hegemonia contemporânea. Detenho-me em Mignolo, entre outros, escutando sobre os fundamentos das culturas e políticas eurocêntricas, produtoras dessa hegemonia.

\subsection{Modernidade}

A modernidade europeia mostra apenas a face benéfica do Renascimento quando associada à racionalidade da emancipação. Volvendo o olhar, revela-se a outra face, sombria, a da irracionalidade intrínseca ao mito racial, à justificação da violência conquistadora, ao muro de contenção ao diálogo com o resto do mundo. Ideologicamente, se opôs a ocidental cultura à natureza indígena. $\mathrm{O}$ livro, a letra e a sua escrita, revestidos já por reverência e privilégio na Europa, foram não só exportados mas reconfigurados para sustentar a mitificação colonial. As prioridades e os modos das reconfigurações 
locais, se questionados a partir das suas concretizações, esclarecem sobre as finalidades em vista.

\subsection{Alfabetismo alfabético}

Mignolo leu de perto e interpretou a evolução e imposição do «alfabetismo alfabético», inscrevendo-o numa cosmovisão ocidental sobre os territórios recém-colonizados de Abya Yala ${ }^{7}$ - em particular do México e do Peru - e sobre o uso imperial da escrita da palavra e dos mapas. Vale a pena conhecer o processo histórico desse alfabetismo de origem europeia: um inquisidor nomeado pelo rei, por volta de 1570, visita as Índias ${ }^{8}$ e, de regresso, elabora recomendações. Aplicadas, elas visavam colher e sistematizar a informação produzida pelas autoridades coloniais sob a coroa de Espanha, tanto de tipo cartográfico como legislativo e regulamentar (2016).

Este alfabetismo alfabético escreveu e difundiu um mito de superioridade europeia baseado na invasão e na raça que o capitalismo comercial, de conquista, incorporou e estruturou.

O espaço ocupado foi representado na cartografia imperial espanhola segundo a visão desse centro europeu de poder, subvertendo e sobreimpondo-se às representações originárias, registando toda a orbe terrestre como domínio possível. A literacia das letras veiculou a norma alfabética ocidental e, ao mesmo tempo, depreciou saberes, sistemas de escrita e de oralidade tornadas subalternas. Mitificado o livro, a escrita e as línguas europeias como virtuosas, em si, e conferentes de estatuto epistémico, os poderes

\footnotetext{
${ }^{7}$ Nome dado à sua terra por povos do centro do continente que o império designou oficialmente, no séc. 17, como América, do nome do explorador ao serviço da coroa, Américo Vespúcio. Este nome é usado atualmente para resgatar um termo endógeno e recusar que todo um continente se denomine numa língua de um poder imperial.

8 Designação dada no séc. 16 aos territórios da atual América, após as invasões europeias.
} 
estatal e de instituições religiosas de vulto produziram e controlaram um sistema de conhecimento letrado e de ensino que consolidou o regime de dominação. Como prioridade, esse sistema formou na visão imperial e depois enquadrou um funcionariado mistamente espanhol e indígena. Produziu crónicas da ocupação e da expropriação num castelhano que viria a ser um crescente instrumento normalizador «do saber e do ser» no continente descoberto. Deixou marcas nas narrativas retornadas à Europa sobre o que eram e o que sabiam os povos que a mesma Europa ignorava que existiam.

Estes acontecimentos históricos ganham relevo por confluírem e se cristalizarem em políticas culturais imperiais.

\subsection{Eurocentrismo}

O eurocentrismo sustentou a superioridade do saber colonial através da mitificação, exportada da Europa, do livro e do «poder da escrita para transformar (e, implicitamente, atualizar) a consciência», partindo da valoração de «missionários e letrados do séc. XVI quando encontraram sociedades sem letras» (Mignolo, 2016, p.148-9), ainda que com formas próprias de escrita sofisticadas (Boone \& Jackson, 2011). Valoração que baseia a «divisória cultural», argumento colonial/ racista refraseado e avançado ao longo do séc. XX.

Para Walter Mignolo, eurocentrismo é o fenómeno, territorial, linguística e agencialmente originado na Europa que «projetou como universal o seu mesmo sentido do mundo e cosmovisão». Centrou numa espacialidade e temporalidade suas, a da modernidade europeia, a autoridade para enunciar o ser, o saber, o crer e o narrar. Das diferenças fez valores, dos valores erigiu normas.

\subsection{Comentários e notas}


Onde os corpos e os territórios esquecidos, apagados, sem estatuto ontológico? Onde a oralidade?

A descolonização do pensamento requer uma outra sabedoria. Boaventura de Sousa Santos fala da sociologia das ausências para estudar os silêncios, as rasuras e deleções operados sobre culturas colonizadas, os questionar e interpretar.

Como imaginar um mundo alternativo, na imersão num presente único, fixado e fechado sobre si?

Visando possibilidades e desejos gerados no afrontamento à subalternização e na resistência à violência sobre as margens, Santos fala, a par, de uma sociologia das emergências, para atender às dinâmicas sociais e culturais do lugar e do presente, a horizontes que abram para um futuro com uma vida justa. Usando a imagem agrária ecológica, concebe um espaço de recusa dos regimes monoculturais, onde os saberes científicos e os artesanais se podem cruzar, hibridar.

Entre as ecologias propostas por Santos, enfoco a «ecologia dos conhecimentos» pela pertinência da reflexão sobre a validação dos saberes anteriormente desacreditados e baseiada em critérios de rigor alternativos. A ecologia dos saberes dirige-se ao reconhecimento e apreço dos modos de conhecer e de criar fora da hegemonia epistémica (Santos, 2012; 2018).

«A credibilidade da construção cognitiva mede-se pelo tipo de intervenção no mundo que proporciona, ajuda ou impede. Como a avaliação dessa intervenção combina sempre o cognitivo com o ético-político, a ecologia de saberes distingue a objectividade analítica da neutralidade ético-política» (Sousa, 2012, p.26).

Uma possibilidade de reconhecimento da oralidade como forma artístico-expressiva, é aberta a partir do conceito de «oratura» desenvolvido por Pio Zirimu, para substituir o de literatura oral que subentende o primado da escrita. Transmitida geracionalmente, essa 
«arte de criar, recriar, transmitir e conservar oralmente composições poéticas, narrativas, dramáticas e outras configurações performativas», integra e nutre um património comunitário (Gomes, 2019). Difícil, pouco comum, é a sua inclusão tanto em bibliotecas/arquivos (Sequeiros, 2017) como em processos de aprendizagem formal. Uma fixação imperativa destas composições pela escrita, pode levar a resultados destrutivos (Gomes, 2019). Atender a condições e oportunidades de «aprendizado» de base oral - salvaguardando a autodeterminação e a soberania intelectual - de recriações artísticas socializadas naqueles ambientes/instituições é uma via que têm sido ensaiada (Sleeper-Smith, 2009) e que à oratura se poderá adequar.

Levantar as cercas cognitivas, cuidar do solo das aprendizagens e de quem aprende, desenvolver projetos de ação formativa colaborativa e interação solidária, reconcetualizar e enquadrar criticamente os processos de formação em literacia da informação é um programa teórico-prático útil e relevante sócio-politcamente.

\section{Referências Bibliográficas}

Alcoff, Linda Martín (2017). A epistemologia da colonialidade de Mignolo. Revista Epistemologias do Sul, 1(1), 33-59.

https://revistas.unila.edu.br/epistemologiasdosul/article/view/786.

Boone, Elizabeth Hill \& Margaret A. Jackson (Eds.). (2011). Their way of writing: scripts, signs, and pictographies in pre-columbian America. Dumbarton Oaks Research Library \& Collection.

Carnoy, Martin \& Félix Blanco (2000). La educación como imperialismo cultural. México: Siglo Veintiuno.

Carnoy, Martin \& Gadotti, Moacir (eds.). (2018). Reinventando Freire: a práxis do Instituto Paulo Freire. São Paulo: Instituto Paulo Freire.

Carvalho, Maria José Paiva Fernandes, Veríssimo, Joaquim, Solovova, Olga, \& Duxbury, Nancy (2018). Publicar sem perecer: sobreviver ao turbilhão: uma iniciativa de formação avançada da biblioteca à comunidade científica. Actas do Congresso Nacional de Bibliotecários, Arquivistas e Documentalistas, 1-4. https://estudogeral.sib.uc.pt/handle/10316/81206. 
Celebrando Paulo Freire: novos e velhos desafios na educação. (2019). Educação, Sociedade \& Culturas, 54, 241 p.

Cortesão, L. (2018a). Contra o desperdício do conhecimento: Paulo Freire ontem e hoje. In M. Carnoy \& M. Gadotti (Eds.), Reinventando Freire: a práxis do Instituto Paulo Freire (pp. 4762). Instituto Paulo Freire.

Cortesão, Luiza (2018b). Prefácio. In Pedagogia do oprimido (5-11). Porto: Afrontamento.

Drucker, Peter F. (1967). The age of discontinuity: guidelines to our changing society. London: Heinemann.

Drucker, Peter F. (1967a). The effective executive. New York: Harper \& Row.

Freire, Paulo (1968). A alfabetização de adultos - critica de sua visão ingênua; compreensão de sua visão crítica. In Ação cultural para a liberdade ( $5^{\mathrm{a}}$ ed.). Rio de Janeiro: Paz e Terra.

Freire, Paulo (1981). Ação cultural para a liberdade: e outros escritos (5a ed.). Rio de Janeiro: Paz e Terra.

Freire, Paulo (1989). A importância do ato de ler (23ª ed.). Brasil: Cortez.

Freire, Paulo (2018). Pedagogia do oprimido. Porto : Afrontamento.

Freire, Paulo \& Donaldo P. Macedo (2011). Alfabetização: leitura do mundo, leitura da palavra [livro digital]. Rio de Janeiro: Paz e Terra.

Freire, Paulo \& Faundez, Antonio (1985). Por uma pedagogia da pergunta. Rio de Janeiro: Paz e Terra.

Gomes, Isabel (2019), "Oratura", Dicionário Alice. https://alice.ces.uc.pt/dictionary/id=23838\&pag=23918\&id_lingua= 1\&entry=24459. ISBN: 978-989-8847-08-9

Guilherme, Maria Manuela Duarte (2018). O diálogo intercultural entre Freire \& Dewey: O Sul e o Norte nas matrizes (pós)-coloniais das Américas. Educação \& Sociedade 39 (142) 89-105.

Mignolo, Walter D. (2016). El lado más oscuro del Renacimiento: alfabetización, territorialidad y colonización. Universidad del Cauca.

Monteiro, H. (2019). Investigação, transformação e «palavramundo»: novos e velhos desafios metodológicos. Educação, Sociedade \& Culturas, 54, 65-84.

Santos, Boaventura de Sousa (2012). Para além do pensamento abissal: das linhas globais a uma ecologia de saberes. Revista Crítica de Ciências Sociais, 78, 3-46. https://doi.org/10.4000/rccs.753.

Santos, Boaventura de Sousa (2018). O fim do império cognitivo: a afirmação das epistemologias do Sul. Coimbra: Almedina.

Schiller, Dan (1999). Digital capitalism: networking the global market system. Cambridge, Mass.: MIT Press. 
Sequeiros, Paula (2017). The Sámi Library, North of the North: colonialism, resistance and reading in a public library. Sociologia: Revista da Faculdade de Letras da Universidade do Porto, 34, 115-134. https://doi.org/10.21747/08723419/soc34a6.

Whitworth, Andrew (2015). Radical information literacy. Chandos Publishing.

Zurkowski, Paul G. (1974). The information service environment relationships and priorities. Related Paper No. 5.

https://eric.ed.gov/?id=ED100391. 